\title{
The League of Nations Library During the War
}

Mr. Rasmussen formerly was head of the Geographical Department of the League of Nations Library at Geneva and now is librarian of the Economic, Financial, and Transit Department of the League at Princeton, N.J. He tells an intimate story of the fortunes of the League library, abroad and in America.

The balance sheet of the First 1 World War appears in the light of ulterior events to contain tragically little to the credit of human intelligence and foresight. But one of its merits was undoubtedly to focus attention on the interdependence of states and make a large number of governments take the first hesitant steps along a road which we now realize must be followed courageously if civilization is to survive. Twenty years of organized world-wide effort to implement this dawning realization created a vast body of experience, theory, law, and literature on international affairs, most of it directly or indirectly connected with the League of Nations. Geneva became, during the inter-war period, the mecca of politicians, government experts, journalists, scholars, and students in a great variety of fields. And out of the documentation required for the study and execution of the numerous tasks entrusted to the League grew a library unique in character and well-adapted to its purpose. By a generous grant from John D. Rocke- feller, Ir., it became possible to extend the library's collections still further and from 1936 to accommodate it in a building which greatly increased its usefulness to the world at large.

Open to any serious student, the League library was sought by increasing numbers who came from distant countries to use its rich source material. It soon became obvious to everybody who worked there that the library corresponded to a need inherent in the trends of modern history-a need that many large European libraries were quite unable to fill.

Political events which during the latter part of the thirties adversely influenced the work of the League were not reflected in any lessening of the activity of the library. On the contrary, the demands on its services constantly increased during this troubled period and it was only shortly before the outbreak of hostilities, and more particularly after May 1940, that the library and its staff were drastically affected.

The harmonious development through which the League library passed up to 1939 would undoubtedly have been continued under normal conditions and increasingly the library would have been of benefit to research work carried out in other parts of the world. But shadows of the approaching war began to fall on the library. The political situation, which had passed from bad to worse, was clearly 
moving apace towards a world-wide conflagration. Crowds of refugees were streaming into Switzerland, and several refugee scholars were already among the familiar faces in the reading rooms. In the spring and summer of 1939 the number of students from foreign countries dropped considerably, and several of those who arrived soon departed with their work unfinished in order to reach safety before the storm broke.

\section{Under War Conditions}

Then came the declaration of war, and a new situation arose. Much of the material contained in the library was naturally of interest in connection with the conduct of military operations. In fact the League library would have been of appreciable interest for military intelligence services if they could have used it at their will. Being part of an international organization to which governments on a considerable scale had furnished official documentation on their respective countries for the promotion of international collaboration and peace, it was evident that measures had to be taken to prevent the library's use for the inverse purposes. Before the outbreak of actual hostilities this had of course not been overlooked by the administration, but abuse in the above sense would for obvious reasons have been impossible to prevent before a state of war existed. All library cards were now canceled and readers obliged to apply for new ones if they desired to continue their studies in the library. A restricted number of cards were subsequently issued with what in the circumstances were considered the necessary precautions, and the staff of the library was asked to bear in mind the possibility of abuse in replying to questions and in furnishing aid and documentation to readers who did not belong to the League secretariat.

In the period from September 1939 to May 1940 the current work of the library functioned with only slight changes. A few members of the library staff had their contracts terminated as part of the overall reduction of personnel which occurred in the course of 1939, but the library's work was not curtailed in any essential respect. Communications with the outside world were still largely intact and, although restrictions were imposed by the belligerents on divulgation of information and on the export of various types of documents, the flow of printed material to the library was on the whole wellmaintained.

\section{Reduction of Staff}

In the middle of May, I940, when the German army was penetrating the Low Countries and France and a catastrophe appeared impending with rumored German troop concentrations on the northern and eastern borders of Switzerland, emergency regulations affecting the entire secretariat were brought into play. A large majority of the officials were given the choice between suspension of their contracts or resignation-with compensation in both cases. A relatively small nucleus of officials was retained, who were to follow instructions issued subsequently.

The measures taken in May 1940 should be considered in the light of the fact that a sudden German invasion of Switzerland was entirely inside the realm of possibilities. The extent to which the League library was affected becomes thus more easily understandable. Of its total staff of twenty-four only two persons, of whom one was the chief librarian, were 
not requested to resign or accept a suspension of contract. Those who accepted suspension were, however, allowed to continue work provisionally but on a very short-term basis. That the great majority tendered their resignation was natural under the circumstances. Not only did financial arrangements favor such solution in most cases but with military events already projecting ulterior developments and with their livelihood menaced, several persons on the library staff desired to reach England or North America before all roads to the free world eventually might be closed. It should be added that the loyalty of the officials toward the library and the secretariat was at no point involved in the decisions to be taken. The instructions received removed any doubt on this point.

Of those who faced the choice only three'French girls chose to continue their work on suspended contracts. The fact that their own country at the moment was rapidly being turned into a battlefield probably prompted this decision in no small degree. While the termination of work for the other officials was effective immediately, it would be appropriate to mention that several of them returned to their work the days following their resignation in order to leave their offices and departments in complete order. This at a moment when preparations for a possible immediate departure were more than a full day's job and the apprehension of being caught in an invasion lent itself to more than academic contemplation.

\section{Change of Policies}

By these drastic measures the working force of the library was reduced from twenty-four persons of eleven national- ities to five persons of whom four were French and one an ex-Austrian. These circumstances, together with the imposition of the strictest economies in all fields, made a complete overhaul of the library's policies an immediate necessity. From May I 5 to July I the library was closed to the public and arrangements were made to adapt its activities to what was considered feasible with the small staff which remained and the severe budgetary restrictions which had been imposed. While considerable economies had already been enacted during the first five months of the year, expenditure during the last seven months of 1940 was actually reduced to between a third and a fourth of that for the same period of 1939 . Salaries of the departing staff counted naturally for a large part of this reduction but expenditure on books and periodicals was also severely cut. Subscriptions to 234 periodicals were canceled and the acquisition of books by purchase was curtailed to an absolute minimum. Also the periodical and other publications published regularly by the library were immediately suspended.

When the library again opened its doors in July, the reduction of personnel and economies of heating, lighting, etc., had necessitated the closing of all reading rooms and the concentration of the services on part of a single floor. Access to the library for persons not belonging to the secretariat had become further restricted. The general public was in principle no longer admitted, and only seventythree authorizations to consult the collections were granted in the last half of I940. These authorizations were mainly issued to representatives of governments and of international organizations and to a few professors and lawyers. In 
place of the reading rooms two or three empty offices were made available, where the desired documentation was arranged and study could take place without supervision.

\section{Difficulties To Be Faced}

It goes without saying that the services which the library under the circumstances was able to render the League secretariat, which by I94I had been reduced to between a sixth and a seventh of its 1939 strength, were very much curtailed and that difficulties of all sorts had to be faced. The handling of the thousands of documents which fortunately still continued to arrive from most governments constituted also a problem. As there was no possibility of cataloging these publications properly, it was decided provisionally to shelflist them and enter one main card in the catalog for each, postponing their adequate treatment to a moment when sufficient personnel could be employed. A still more important problem was, however, to be found in the fact that several governments soon ceased to send their publications altogether or in part (presumably on account of the hazards involved in transportation and in order to prevent important documents from falling into enemy hands in transit) and that bibliographic information on what was being published in a number of countries steadily became more difficult to obtain.

In the long run this situation would undoubtedly have affected the future standards of the library's collections most seriously if some means of counteracting it had not been found. The League library, which was ideally situated for acquiring the documentation obtainable from the European continent, was, vis-àvis the rest of the world, in much the same situation as American libraries vis-à-vis Europe. In order to prevent unnecessary gaps in its sets of periodicals, annuals, etc., especially government documents, a request was addressed by the League library to extra-European governments and institutions which had ceased to send their publications, asking them to store this material until circumstances later would permit its transfer to Geneva. The extent to which we may presume that such a request is being followed varies from one country to another. The probability is that countries where stocks of public documents rapidly become exhausted and that governments which possess a complicated and decentralized organization for printing, exchange, and distribution, will fail to respond in a satisfactory manner. Some, perhaps, in the rush of war activities may take no action at all in the matter. The vast changes which have occurred in the field of publications during the last few years would also in part remain uncovered by this arrangement. As we shall see later, developments inside the secretariat helped to offset this disadvantage in no small measure.

\section{Acquisitions}

The purchases made by the library since May 1940 have been aimed at safeguarding, as far as possible, the library's future position as an international center of documentation. The main principles followed have been, on the one hand, to acquire all essential material which supposedly might not be available after the war on account of the restricted number of copies in which publications in many countries are now being issued; and, on the other, to effect the library's economies on publications which are likely to 
be procurable on the market for some time to come. By following this policy the library has been able to acquire many publications which will be hard to locate elsewhere after the end of hostilities and perhaps impossible to buy. But the policy has, of course, also had the effect of interrupting, at least temporarily, many of the library's serial and periodical publications, particularly in the general, technical, health, and social fields. There is some prospect, however, that these gaps may later be filled. As regards reference books, purchase was limited to what was considered absolutely indispensable and expensive works available in the Geneva University Library were not duplicated in the League library. Also the binding had to be reduced to a minimum standard of quality and was limited to a restricted number of volumes per year.

In 194I the chief librarian departed and Monsieur Henri Vigier, political counselor in the secretariat, was charged with the administration of the library as one of his duties. It now became possible to re-engage on a temporary basis two of the library's former officials-who had remained in Geneva and also to resume publication of the Monthly List of Selected Articles, which had been suspended in 1940. The gap which existed between its last issue and the date of resumption was subsequently filled. As a large number of copies of this index previously had been used.for exchange purposes, it filled for the library a strongly felt need in a period of heavy budgetary restrictions. Being probably the only international periodical index at present published on the European continent, it possesses considerable interest. Although the number of periodicals indexed has naturally been reduced, it still comprises several hundreds.

With its funds for acquisition of publications cut in 1940 to less than half of I939 expenditure, and in I94I and 1942 to less than a fourth, the library nevertheless had an accession of about 8000 volumes and 1350 periodicals in I94I and about 4600 volumes and pamphlets and 1200 periodicals in 1942 . During the three'years 1940 to 1942 three fourths of the expenditure for acquisitions were spent for keeping the most essential periodical sets intact. Attempts were also made to develop the library's exchange relations, which had suffered by the sudden reduction of the League's publication activities. But with Switzerland situated as an island in an Axis-occupied Europe and communications becoming increasingly hampered, the situation as regards the library's documentation from the extraEuropean world was gradually growing worse.

It has been mentioned above that developments inside the secretariat helped to compensate this situation, which had become particularly serious after the occupation of the entire French metropolitan territory in the autumn of 1942 . When the maintenance of satisfactory communications with the outside world in the summer of 1940 had entered a precarious stage for the conduct of many of the League's technical activities, the major part of the Economic, Financial, and Transit Department, including its director, was sent on mission to Princeton, N.J., there to continue its work on world economic problems. A joint invitation from three American academic bodies, i.e., Princeton University, the Rockefeller Institute for Medical Research, and the Institute for Advanced Study, made this practicable. On its arrival the mission 
took up quarters in the Institute for Advanced Study, where offices and other facilities were put at its disposal. Only a few key documents were brought over and no librarian accompanied the mission. An estimate of working possibilities as far as documentation was concerned could obviously not be made in any detail before the mission's arrival, and the task of organizing this part of the work was left to arrangements to be made on the spot. When the mission settled down to work the necessity of obtaining a librarian who was familiar with the League's work, international documentation, and the League's library practices became obvious.

\section{The Librarian's Task}

On his arrival in the United States in January I94I, the writer was therefore entrusted with this end of the mission's work. The immediate object of his duties was to provide and organize the documents and other publications required for the work of the department. This had to be done as rapidly as possible, with a minimum of personnel and expense and, it may be added, in circumstances where the absence of sufficient physical equipment, room, and professional assistance was a constant worry. In spite of the many obstacles, however, the task was carried out, and at the present moment the library has an annual accession of over three thousand volumes and pamphlets, receives between six and seven hundred periodicals regularly, and circulates over eight hundred to the department, while its interlibrary loans amount to several thousands per annum.

In view of the fact that this work has had to be carried out by a library personnel of only two persons, who are also charged with a considerable amount of reference work and bibliographic research and have to carry on a voluminous correspondence with government departments and institutions all over the world, it may be understood that resort to shortcuts in several of the technical processes has been inevitable. It has thus not been possible to catalog more than part of the collections, and the library's efficiency naturally depends to a larger extent on the knowledge of its personnel than would be the case in normal circumstances.

As for documentation, the department's work could scarcely have been carried on without the close collaboration of other libraries, on whose resources the League of Nations library branch has been able to draw heavily. Arrangements for extensive interlibrary loans from Princeton University Library, situated about two miles from the Institute for Advanced Study, have been functioning since the first months of I94I and have been of invaluable assistance. The numerous volumes borrowed from that library as well as from other large libraries in the United States have also made it possible to avoid purchases which would duplicate material already found in the League's library in Geneva; it has further prevented the increase of collections far beyond the physical capacity of the available premises.

Similar advantages have been obtained from the mission's direct access to the Library of the Institute for Advanced Study, of whose periodicals the League library branch circulates many to the members of the department. In addition the institute has generously acquired a number of publications which were needed for constant use, the acquisition of which 
by the League library branch would have entailed duplication of the Geneva collections.

Although interlibrary loans from Princeton University Library and a few other large libraries have been a one-way traffic, the League library branch has on several occasions lent publications to government agencies and libraries when the material was not otherwise available in this country. A number of persons have also visited the library to study specific documentation which could not be had in Washington and New York.

The policy followed in regard to acquisitions at the Princeton branch has primarily been governed by the needs of the department. While the mission at Princeton deals particularly with the extra-European world and the staff in Geneva concentrates on developments on the European continent, a similar division of work, though more as a matter of emphasis than of distinction, has developed for the two libraries. The state of postal communications has naturally been decisive for the areas from which documents have been obtainable here and in Europe but, although duplications have been inevitable, the two collections are, according to available information, largely complementary.

\section{Cooperating with Library in Geneva}

From the time of the planning of the library branch in Princeton attention has been paid to the desirability of coordinating acquisitions with those of the League library in Geneva. With the future in mind lists of non-European publications which no longer arrived in Geneva were requested and obtained in the spring of I94I. Other lists followed, and it became possible to acquire here a consider- able number of such documents which presumably will prove unobtainable at a later stage. Although sinkings, delays in transportation, and changes in postal communications as well as in the decisions of governments concerning dispatch of their publications to Geneva made this correlation difficult and imperfect, great advantage has definitely been derived from the different geographical situations of the two libraries during the war and many irretrievable gaps in their combined collections have been avoided.

Until the end of hostilities in the European theatre it will not be possible to form a complete picture of the damage which the war has indirectly caused to the documentation of the League of $\mathrm{Na}$ tions Library. As regards European material published during the war period, the Geneva library is no doubt in its fields-in spite of its restricted budgetin a far better position than any library in this hemisphere and ranks probably very high among European libraries. It should not be forgotten that very few large libraries in Europe have been able to function on a normal basis since 1940 and that, with a few German exceptions, no other library on the continent is likely to possess so substantial and representative collections of the more interesting material which has appeared during the last three or four years. What will happen, or perhaps already has happened, to the few German libraries referred to, which are nearly all situated in cities subject to intense aerial bombardment, may be left to the speculations of those familiar with the rising tide of air warfare.

The Geneva library's extra-European collections for the war period have on the other hand been considerably dented but 
presumably only temporarily. When at the end of the war in Europe the collections of the Princeton branch and the deposits constituted in a good many countries are transferred to Geneva, it is a reasonable assumption that the League library will ultimately turn out to have survived the crisis with few scars. The drastic reductions of budget and personnel that have obtained since the middle of 1940 will make much technical work and many acquisitions necessary if the library is to reach as high a standard for its wartime material as for its prewar material. But the fact that its deficiencies will be mainly in overseas publications, which should still be obtainable at a later stage, should enable it to recover rapidly and play its proper part in the postwar world.

\section{An Analysis of $\{$ ibrary Duties}

To LIBRARIANS concerned with the study of activities, an item which appeared in the October 1943 number of the Bulletin of the Medical Library Association may be of interest. It is entitled "Work Analysis of Functions and Duties of the Medical Library Staff" and was prepared by Jennie R. Greenbaum, head of the Florsheim Memorial Library at the Michael Reese Hospital in Chicago. The various functions the article lists are classified according to the qualifications required to perform them. An incidental value of the statement is suggested by the fact that it was drawn up to familiarize a superior officer with the way the members of the staff used their time and with the reasons for augmenting that staff. 